\title{
Does noninvasive ventilation work in ARDS? A case report and review of the current literature
}

\author{
P Malhotra, S K Jindal
}

Emerg Med J 2005;22:745-746. doi: 10.1136/emj.2003.013995

The role of noninvasive positive pressure ventilation (NIPPV) in adult respiratory distress syndrome (ARDS) is controversial, in contrast to its well established benefits in other types of respiratory failure, especially acute exacerbations of chronic obstructive pulmonary disease and cardiogenic pulmonary oedema. We report a case of ARDS caused by Mycoplasma pneumoniae in a 70 year old man, treated with NIPPV in addition to standard medical therapy and analyse current evidence regarding the role of NIPPV in patients with ARDS.

\footnotetext{
A
} 70 year old retired police inspector presented to the emergency department with a 10 day history of fever followed by rapidly progressive dyspnoea for 3 days prior to admission. He was a non-smoker and teetotaller and there was no prior history of any medical illness. Physical examination revealed marked tachypnoea (respiratory rate 40 breaths/min), central cyanosis, and extensive fine inspiratory crackles on auscultation of the chest. Haemogram revealed haemoglobin $124 \mathrm{~g} / \mathrm{l}$ and total leukocyte count $30000 / \mathrm{mm}^{3}$ with a differential of $84 \%$ neutrophils, $9 \%$ lymphocytes, $5 \%$ monocytes, and $2 \%$ eosinophils. Erythrocyte sedimentation rate was $35 \mathrm{~mm}$ /hour and platelet count $263000 / \mathrm{mm}^{3}$. Renal and liver function tests were within normal limits. There was severe type 1 respiratory failure on arterial blood gas analysis (table 1). Chest $x$ ray revealed bilateral diffuse alveolar infiltrates with normal cardiac size (fig 1A). The patient therefore fulfilled three of the four criteria for the diagnosis of ARDS. ${ }^{1}$ Extensive ground glassing was observed on high resolution computed tomography (CT) scan of the chest (fig 1B). Serum cold agglutinins were positive, with a titre of 1:64. Blood culture was sterile and there was no evidence of deep venous thrombosis on compression ultrasound of the lower limbs.

Broad spectrum antibiotics (intravenous cefotaxime and levofloxacin) and high flow oxygen $\left(\mathrm{FiO}_{2}\right.$ 0.5) were administered with no significant improvement in either clinical condition or blood gases over the next 48 hours (table 1). The patient was shifted to the respiratory intensive care unit (RICU) of the Institute, anticipating the need for mechanical ventilation. In the RICU, he was put on NIPPV (VPAPII, Resmed) with a nasal mask in addition to the treatment already being given. Initial settings were inspiratory positive airway pressure (IPAP) of $8 \mathrm{~cm} \mathrm{H}_{2} \mathrm{O}$ and expiratory positive airway pressure (EPAP) of $4 \mathrm{~cm} \mathrm{H}_{2} \mathrm{O}$. Within an hour of starting ventilation there was marked improvement in respiratory rate, which fell from 40 to 22 breaths/min, dyspnoea decreased, and a significant improvement in blood gases was noted (table 1). This improvement was sustained and progressive except for episodes of severe desaturation when removal of the mask was required for eating and drinking. The maximum pressures administered during his hospital stay were IPAP
12 and EPAP $8 \mathrm{~cm} \mathrm{H}_{2} \mathrm{O}$. Levels of IPAP and EPAP were gradually reduced as the patient's clinical condition and blood gases showed a steady improvement. He was discharged after a hospital stay of 11 days with a satisfactory arterial blood gas result in room air, and advised to continue levofloxacin for a period of 3 weeks. On follow up a month later, the patient was asymptomatic, his cold agglutinin titres had declined to $1: 8$, and there was almost complete clearing on chest $x$ ray.

\section{DISCUSSION}

It is now recognised that Mycoplasma pneumoniae, traditionally believed to cause mild disease, is the aetiological agent in about $2-7 \%$ cases of severe community acquired pneumonia (CAP). ${ }^{23}$ However, ARDS due to M. pneumoniae is distinctly unusual, with only sporadic case reports in the English literature. $^{45}$

NIPPV has now assumed a central role in the management of hypercapnic respiratory failure due to chronic obstructive pulmonary disease (COPD) and in cardiogenic pulmonary oedema; however, its role in ARDS secondary to severe pneumonia is highly controversial. Early studies comprising a heterogenous group of patients with acute respiratory failure treated with NIPPV suggested that pneumonia was a poor prognostic factor. As an illustration, in Antonelli's study, ${ }^{6}$ all patients with pneumonia randomised to NIPPV failed therapy, whereas there was a $60 \%$ success rate in those patients in whom respiratory failure was not attributable to pneumonia. The authors speculated that the higher failure rate in patients with pneumonia was due to difficulty clearing secretions, reduced pulmonary compliance, and nonhomogeneous gas exchange. Analysis of the first randomised trial of NIPPV in 56 patients with pneumonia revealed that only the subgroup of patients who had concomitant COPD appeared to benefit from NIPPV.?

In a study by Rocker et $a l^{8}$ there was a $66 \%$ success rate when NPPV was used as the initial mode of assisted ventilation in 10 patients with ALI/ARDS. More recent data

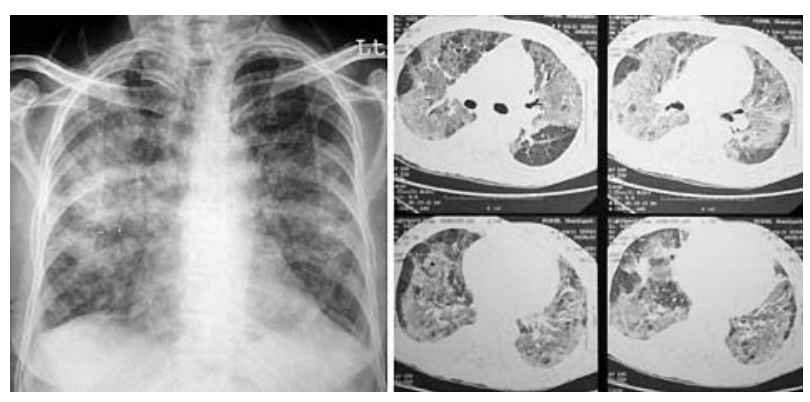

Figure 1 Left panel, bilateral alveolar infiltrates on chest $x$ ray with normal cardiac size consistent with ARDS; right panel, a series of high resolution chest $\mathrm{CT}$ scans demonstrating bilateral extensive ground glass opacities. 
Table 1 Sequential arterial blood gas values demonstrating severe type 1 respiratory failure at admission that persisted in spite of antibiotics and high flow oxygen, and subsequent marked improvement with noninvasive positive pressure ventilation

\begin{tabular}{lllll}
\hline & $\begin{array}{l}\text { At admission } \\
\left(\mathrm{FiO}_{2} \text { 0.5) }\right.\end{array}$ & $\begin{array}{l}\text { Day 3 of } \\
\text { antibiotics } \\
\left(\mathrm{FiO}_{2} \text { 0.5) }\right.\end{array}$ & $\begin{array}{l}\text { On NIPPV } \\
\text { (IPAP 8, } \\
\text { EPAP 4) }\end{array}$ & $\begin{array}{l}\text { At discharge } \\
\text { (room air) }\end{array}$ \\
\hline $\mathrm{PaO}_{2}$ & 48 & 50 & 86 & 67 \\
$\mathrm{PaCO}_{2}$ & 23 & 21 & 31 & 34 \\
$\mathrm{SaO}_{2}$ & 86 & 88 & 97 & 93 \\
$\%$ & & & \\
$\mathrm{HCO}$ & 20 & 19 & 22 & 22 \\
$\mathrm{pH}$ & 7.48 & 7.49 & 7.44 & 7.43 \\
\hline
\end{tabular}

exclusively from non-COPD patients with severe CAP revealed that 22 of 24 patients had initial improvements in oxygenation and respiratory rates after starting NIPPV but that $66 \%$ of the study patients eventually required intubation. ${ }^{9}$ The authors found that patients whose respiratory rates decreased at the end of the first hour of NIPPV were less likely to require intubation than those in whom the respiratory rate either remained stable or increased. Our patient had shown a significant decrease in respiratory rate as well as dyspnoea at the end of the first hour of NIPPV. However, we feel that this dictum of clinical improvement at 1 hour predicting a successful outcome of NIPPV is applicable more to cases of COPD than severe pneumonia, as the latter is characterised by alveolar filling, ventilation perfusion mismatch, and decreased pulmonary compliance, all of which are less rapidly reversible than the hypercapnic respiratory failure of COPD, in which respiratory muscle fatigue plays a predominant role. The most recent and largest study (105 patients) to address the issue of NIV in severe pneumonia found that the use of non-invasive ventilation compared with high concentration oxygen therapy decreased the need for intubation, the incidence of septic shock, and intensive care unit mortality, even though the seven patients with ARDS had a poor outcome (five died). ${ }^{10}$ Current evidence therefore suggests, as was demonstrated in our case, that NIPPV is warranted in most patients of ARDS due to severe community acquired pneumonia not responding to standard medical therapy. However, as intubation rates are high, NIPPV should ideally be used in such patients with a conventional mechanical ventilator on standby. It is the subgroup of patients with relatively mild, early ARDS who are likely to benefit from NIPPV and avoid intubation.

\section{LEARNING POINTS}

- Mycoplasma pneumoniae can cause ARDS in adults

- NIPPV is warranted as a "bridge" in patients with ARDS due to severe pneumonia until antibiotics take effect.

- NIPPV is especially likely to benefit patients with a rapidly reversible cause of ARDS.

\section{Authors' affiliations}

P Malhotra, S K Jindal, Department of Pulmonary Medicine,

Postgraduate Institute of Medical Education and Research, Chandigarh, India

Competing interests: there are no competing interests.

Correspondence to: Dr S K Jindal, Department of Pulmonary Medicine, Postgraduate Institute of Medical Education and Research, Chandigarh 160012, India; skjindal@indiachest.org

Received 22 December 2003

In revised form 20 February 2004

Accepted 1 April 2004

\section{REFERENCES}

1 Bernard GR, Artigas A, Brigham KL, et al. The American-European Consensus Conference on ARDS: Definitions, mechanisms, relevant outcomes and clinical trial coordination. Am J Resp Crit Care Med 1994;149:818-24.

2 Torres A, Serra-Batlles J, Ferrer A, et al. Severe community acquired pneumonia. Epidemiology and prognostic factors. Am Rev Respir Dis $1991 ; 144: 312-18$.

3 Moine $\mathbf{P}$, Vercken JB, Chevret $\mathrm{S}$, et al. Severe community acquired pneumonia. Etiology, epidemiology and prognostic factors. French Study Group for Community-Acquired Pneumonia in the Intensive Care Unit. Chest 1994; 105: 1487-95.

4 Shah DC, Muthiah MM. Adult respiratory distress syndrome due to Mycoplasma pneumonia. Postgrad Med J 1996;72:241-2.

5 Chian CF, Chang FY. Acute respiratory distress syndrome in Mycoplasma pneumonia: a case report and review. J Microbiol Immunol Infect 1999;32:52-6

6 Antonelli M, Conti G, Rocco $M$, et al. A comparison of noninvasive positive pressure ventilation and conventional mechanical ventilation in patients with acute respiratory failure. N Engl J Med 1998;339:429-35.

7 Confalonieri M, Potena A, Carbone G, et al. Acute respiratory failure in patients with severe community acquired pneumonia: a prospective randomized evaluation of noninvasive ventilation. Am J Resp Crit Care Med 1999; 160:1585-91.

8 Rocker GM, Mackenzie MG, Williams B, et al. Noninvasive positive pressure ventilation. Successful outcome in patients with acute lung injury/ARDS. Chest 1999; 115:173-7.

9 Jolliet $\mathbf{P}$, Abajo B, Pasquina $P$, et al. Non-invasive pressure support ventilation in severe community acquired pneumonia. Intensive Care Med $2001 ; 27: 812-21$.

10 Ferrer M, Esquinas A, Leon $M$, et al. Noninvasive ventilation in severe hypoxemic respiratory failure: A randomized clinical trial. Am J Resp Crit Care Med 2003; 168:1438-44 


\title{
Ring down artefacts on abdominal sonography to predict pulmonary abnormalities in the emergency department
}

\author{
C-L Tsai, H-P Wang, W-C Lien, C-C Chen, T-I Lai, W-J Chen
}

Emerg Med J 2005;22:747-748. doi: 10.1136/emj.2004.016352

Ring down artefacts are sometimes found when emergency physicians perform abdominal ultrasound to differentiate between various abdominal problems. We describe a patient who presented with right upper quadrant abdominal pain and whose ultrasound examination showed ring down artefacts posterior to the right hemidiaphragm, which led to the eventual diagnosis of pneumonia. Ring down artefacts on ultrasound may be used to predict pulmonary abnormalities. Awareness of this sonographic finding may assist in accurate diagnosis and administration of appropriate treatment without delay.

E mergency physicians (EPs) frequently encounter abdominal complaints. Abdominal ultrasound (US) is of great assistance in differential diagnosis of these problems. However, during the abdominal US examination, meaningful artefacts are sometimes seen. In particular, posterior to the liver, the examiner may encounter multiple, vertical, long and narrow bands or lines trailing down from the posterior surface of the right hemidiaphragm, the so-called "ring down" artefacts. We describe a patient whose US examination showed these ring down artefacts, which contributed to his final diagnosis of pneumonia. We discuss the implications of these findings for EPs.

\section{CASE REPORT}

A 58 year old man presented to the emergency department (ED) with sudden onset of right upper quadrant abdominal pain. No fever, diarrhoea, or nausea was noted. He was a heavy smoker who had suffered from chronic productive cough for years. He denied other significant past medical or surgical history. On arrival, blood pressure was 113/59 mmHg and body temperature was $38^{\circ} \mathrm{C}$. On physical examination, the breath sounds were relatively clear. The abdomen was soft, and there was a positive Murphy's sign. Laboratory examinations showed leucocytosis with white blood cell count of $13.870 / \mathrm{ml}$ and $80 \%$ neutrophils. Aspartate aminotransferase and bilirubin values were within normal limits. Emergency US was performed by an EP, working on suspicion of acute cholecystitis. However, the US did not show gallstones or wall thickening of gall bladder, which would have supported the diagnosis of acute cholecystitis. Instead, numerous ring down artefacts posterior to the right hemidiaphragm were disclosed with the US probe placed transversely, right subcostally, and in the cephalic direction (fig 1), which led to suspicion of abnormalities in the right lung base. Chest radiography was subsequently performed, and showed increased lung markings at the right lower lung. Finally, pneumonia was diagnosed and the patient was treated with intravenous antibiotics. He was discharged uneventfully 10 days later and his follow up chest $x$ ray showed complete resolution.

\section{DISCUSSION}

Traditionally, ring down artefacts have been thought to be similar to the comet tail artefacts the are associated with foreign bodies, particularly metallic objects and cholesterol crystals. ${ }^{12}$ These two artefacts are both reverberation artefacts, producing a series of parallel bands radiating from their sources. They appear when a large mismatch in acoustic impedance occurs between two types of tissue. This interface has two effects: firstly, as it reflects $99 \%$ of the sound beam and produces strong reverberation artefacts parallel to the transducer, the interface totally obscures the underlying tissue, and secondly, it generates showers of vertical echo that will be projected into the underlying tissue. ${ }^{3}$

Avruch and Cooperberg postulated that ring down artefacts appear because of multiple reflections of the US pulse occurring between air bubbles of the lung parenchyma. ${ }^{4}$ Lim et al further speculated that the distribution and extent of ring down artefacts posterior to the right hemidiaphragm may depend on the distribution and the severity of abnormalities in the right lung base. ${ }^{5}$ They found that various pulmonary diseases can show ring down artefacts on US scan. In their study, when the pulmonary abnormalities are localised, ring down artefacts are seen focally at the area of abnormalities. In contrast, nearly all cases of idiopathic interstitial pneumonia elicit numerous ring down artefacts..$^{5}$ In our case, although the patient's Murphy's sign was positive, it did not carry sufficient weight to establish the diagnosis of cholecystitis. ${ }^{6}$ Furthermore, clinical presentation with right upper quadrant abdominal pain has been reported to be associated with pulmonary pathologies, such as pulmonary embolism or tension pneumothorax. ${ }^{78}$ Therefore, abdominal US serves a crucial role to confirm diagnosis in patients presenting with right upper quadrant abdominal pain.

Ring down artefacts were found in our patient and redirected the physicians to the possibility of pneumonia. The case underlines the importance of ring down artefactsthat is, to remind clinicians that the possible diagnosis may be located above the diaphragm.

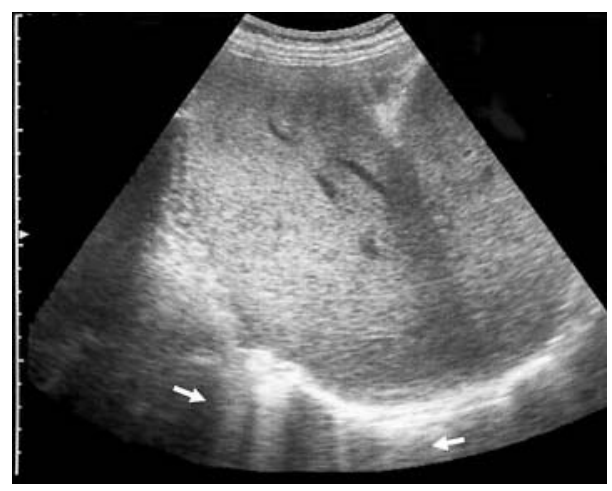

Figure 1 Abdominal sonogram shows numerous ring down artefacts (arrow) posterior to the aspect of the right hemidiaphragm.

Abbreviations: ED, emergency department; EP, emergency physician; US, ultrasound 
Ring down artefacts may also be seen in conditions ranging from non-significant focal interlobular septal thickening to diffuse interstitial fibrosis. In deciding whether the artefacts are meaningful or not, the number of artefacts becomes an important index. There have been reports showing that $<5$ ring down artefacts are seen in 28-68\% of normal healthy individuals. ${ }^{9}$ "Numerous" ring down artefacts, however, may implicate pulmonary pathological conditions in 95\% patients, as in our patient. ${ }^{5}{ }^{10}$ Numerous ring down artefacts, also called the "aurora sign", have been proved by three dimensional computed tomography to be derived from the irregularity of air spaces immediately below the pleura. ${ }^{10}$

In conclusion, the ring down artefacts seen using US may be used to predict pulmonary abnormalities in the ED. When EPs encounter ring down artefacts posterior to the right hemidiaphragm while performing abdominal US for evaluation of right upper quadrant pain, they should consider pulmonary abnormalities in addition to abdominal problems. Awareness of this sonographic finding may assist in accurate diagnosis and administration of appropriate treatment without delay.

\section{Authors' affiliations}

C-L Tsai, H-P Wang, W-C Lien, T-I Lai, W-J Chen, Department of Emergency Medicine, National Taiwan University Hospital and National Taiwan University College of Medicine, Taipei, Taiwan

C-C Chen, Department of Internal Medicine, National Taiwan University Hospital and National Taiwan University College of Medicine, Taipei, Taiwan
Competing interests: none declared

Correspondence to: Dr C-L Tsai, Department of Emergency Medicine, National Taiwan University Hospital, No. 7, Chung-Shan South Road, Taipei, 100, Taiwan; chulintsai@ntu.edu.tw

Accepted for publication 10 May 2004

\section{REFERENCES}

1 Shapiro R, Winsberg F. Comet-tail artifact from cholesterol crystals: Observations in the postlithotripsy gallbladder and an in vitro model. Radiology 1990;177:153-6.

2 Ziskin MC, Thickman DI, Goldenberg NJ, et al. The comet-tail artifact. $J$ Ultrasound Med 1982;1:1-7.

3 Kremkau FW, Taylor KJW. Artifacts in ultrasound imaging. J Ultrasound Med 1986;5:227-37.

4 Avruch L, Cooperberg PL. The ring-down artifact. J Ultrasound Med 1985:4:21-8.

$5 \mathrm{Lim}$ JH, Lee KS, Kim TS, et al. Ring-down artifacts posterior to the right hemidiaphragm on abdominal sonography: sign of pulmonary parenchymal abnormalities. J Ultrasound Med 1999;18:403-10.

6 Trowbridge RL, Rutkowski NK, Shojania KG. Does this patient have acute cholecystitis? JAMA 2003;289:80-6.

7 Unluer EE, Denizbasi A. A pulmonary embolism case presenting with upper abdominal and flank pain. Eur J Emerg Med 2003;10:135-8.

8 Hollins GW, Beattie T, Harper I, et al. Tension pneumothorax: report of two cases presenting with acute abdominal symptoms. J Accid Emerg Med $1994 ; 11: 43-4$

9 Lichtenstein D, Meziere G, Biderman P, et al. The comettail artifact: An ultrasound sign of alveolar-interstitial syndrome. Am J Respir Crit Care Med 1997; 156:1640-6.

10 Kohzaki S, Tsurusaki K, Uetani $M$, et al. The aurora sign: an ultrasonographic sign suggesting parenchymal lung disease. Br J Radiol 2003;76:437-43.

\section{Brugada syndrome, manifested by propafenone induced ST segment elevation}

\section{E Aksay, T Okan, S Yanturali}

\begin{abstract}
We report a case of a 43 year old man who was diagnosed with Brugada syndrome after propafenone administration for chemical cardioversion of new onset atrial fibrillation. Brugada syndrome has been described in the medical literature and is thought to be responsible for the majority of sudden cardiac deaths in patients without ischaemic heart disease. This syndrome has not yet been extensively discussed in the emergency medicine literature despite its importance. Emergency physicians should consider Brugada syndrome in patients who present to the emergency department with right bundle branch block and ST segment elevation in the right precordial leads, which is the classic electrocardiographic pattern of this syndrome.
\end{abstract}

$\mathrm{V}$ entricular fibrillation (VF) is the main cause of sudden cardiac death (SCD). Most SCDs are associated with acute coronary ischaemia near the time of death. However, $10-20 \%$ of SCD patients have no evidence of structural or ischaemic heart disease, and these patients have been referred to as having "idiopathic $V^{\prime} F^{1{ }^{1}}{ }^{2}$ Brugada syndrome (BS) is now suspected to be responsible for 40 $60 \%$ of cases of idiopathic VF. ${ }^{3}$

\section{CASE REPORT}

A 43 year old man presented to the emergency department (ED) complaining of palpitations, which hadstarted 1 hour prior to presentation. He denied syncope or chest pain. Blood pressure was 135/76 mmHg, pulse 138 beats/min, $\mathrm{O}_{2}$ saturation $98 \%$, respiratory rate 14 breaths/min, and temperature $36.0^{\circ} \mathrm{C}$. Past medical history included a negative treadmill stress test for atypical chest pain 1.5 years previously, as his mother had died of sudden cardiac death (SCD) at 44 years of age. The patient was placed on a monitor and an intravenous catheter was inserted. The initial ECG demonstrated atrial fibrillation with rapid ventricular response (134 beats/min) and incomplete right bundle brunch block (RBBB) without ST segment elevation (fig lA). A prior ECG, which was obtained for comparison, showed sinus rhythm with RBBB and $1 \mathrm{~mm}$ ST elevation in leads Vl-2. Intravenous diltiazem (40 mg) was administered, which achieved rate control. Complete blood count, serum electrolytes, and initial cardiac markers were normal.

Abbreviations: $B S$, Brugada syndrome; $E D$, emergency department; $I C D$, implantable cardioverter defibrillator; RBBB, right bundle brunch block; SCD, sudden cardiac death; VF, ventricular fibrillation; VT, ventricular tachycardia 
A
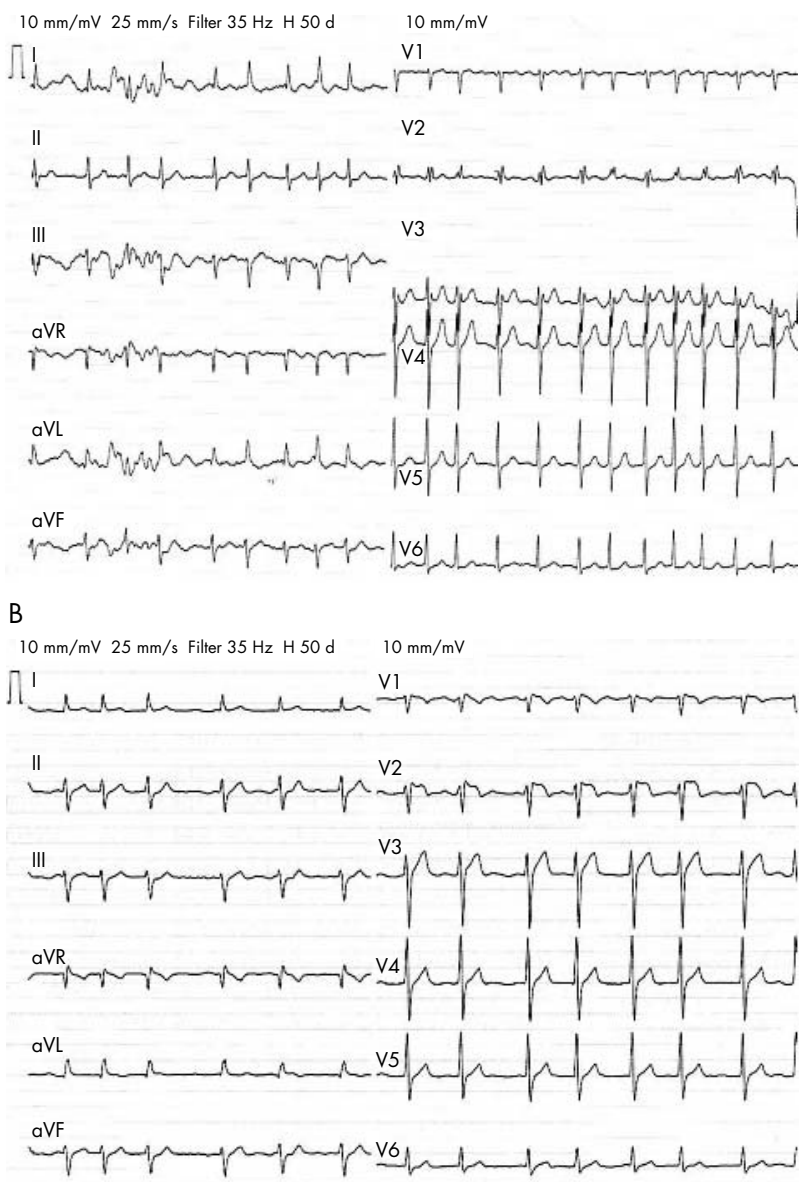

C

$10 \mathrm{~mm} / \mathrm{mV} 25 \mathrm{~mm} / \mathrm{s}$ Filter $35 \mathrm{~Hz} \mathrm{H} 50 \mathrm{~d} \quad 10 \mathrm{~mm} / \mathrm{mV}$
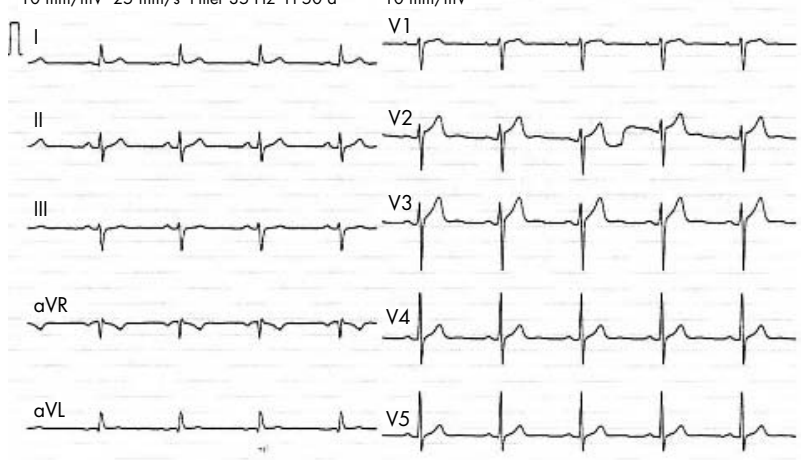

aVF

Figure 1 (A) Initial ECG: atrial fibrillation with rapid ventricular response and incomplete RBBB, with no evidence of Brugada syndrome. (B) Repeat ECG after propafenone administration: 1-3 mm ST segment elevation in leads $\mathrm{V} 1-3$, and $\mathrm{T}$ wave inversion in $\mathrm{V} 1$ and $\mathrm{V} 2$. (C) ST segment elevation and RBBB resolved and atrial fibrillation converted to sinus rhythm.

Because atrial fibrillation was considered as new onset, $600 \mathrm{mg}$ of propafenone was administered orally to achieve chemical cardioversion. After 6 hours, a repeat ECG showed l-3 mm ST segment elevation in leads $\mathrm{Vl}-3$, and $\mathrm{T}$ wave inversion in leads V1 and V2 (fig lB). The patient denied any chest pain or angina equivalent during the observation period. Cardiology consultation was obtained because of suspected silent acute myocardial infarction, and repeat
Table 1 Diagnostic criteria for Brugada syndrome

(1) Appearance of a coved type ST segment elevation (gradually descending terminal portion) in more than one right precordial lead, in the presence or absence of a sodium channel blocker and one of the following clinical criteria:

Documented ventricular fibrillation

Self terminating polymorphic VT

Family history of SCD ( $<45$ years)

Coved type ECGs in family members

Electrophysiological inductibility

Syncope or nocturnal agonal respiration

The appearance of the ECG features, without these clinical symptoms, is referred to as an idiopathic Brugada ECG pattern (not BS)

(2) Appearance of saddle back type ST segment elevation (terminal portion $>1 \mathrm{~mm}$ ) in more than one right precordial lead under baseline conditions with conversion to coved type following challenge with a sodium channel blocker. Drug induced ST segment elevation $>2 \mathrm{~mm}$ should raise the possibility of BS when one or more of the aforementioned clinical criteria are present.

(3) Appearance of saddle back type ST segment elevation (terminal portion $<1 \mathrm{~mm}$ ) in more than one lead under baseline conditions with conversion to coved type following challenge with a sodium channel blocker.

Table 2 Treatment criteria for Brugada syndrome

All symptomatic patients and inducible asymptomatic patients should be treated.

Non-inducible asymptomatic patients should be observed with follow up, and treatment is not recommended for these patients.

cardiac markers were ordered. Subsequently, ST segment elevation was persistent for 6 hours and then progressively declined to baseline. Additionally, atrial fibrillation converted to sinus rhythm, and the RBBB resolved (fig $1 \mathrm{C}$ ). At 12 hours, cardiac markers were not elevated. The patient was admitted to the coronary care unit with a diagnosis of suspected BS.

The following day, echocardiography and coronary angiography were performed, which revealed no evidence of structural heart disease. Programmed ventricular stimulation was also performed but it failed to induce ventricular tachycardia (VT) or VF. The patient was discharged on the third day of admission with the diagnosis of BS.

\section{DISCUSSION}

BS was first described by Pedro and Josep Brugada in 1992. The syndrome is characterised by SCD or episodes of syncope resulting from polymorphic VT or VF in previously healthy people, with the classic ECG finding of RBBB and ST segment elevation in the right precordial leads. ${ }^{4}$ Patients with BS may be completely asymptomatic, and are often recognised by chance because of ECG screening for insurance, sport licensing, atypical complaint, or investigation of other family members with known BS. Therefore, BS should be considered and investigated in patients with the characteristic ECG pattern, even if they are asymptomatic.

BS is a primary electrical disorder resulting in abnormal electropyhsiological activity, and is typically seen in the fourth or fifth decade of life in men. ${ }^{5}$ Although the syndrome has autosomal dominant transmission, sporadic cases have been reported. ${ }^{3}$ Mutation of the SCN5A gene, which encodes for cardiac sodium channels, causes loss of cardiac sodium channel function, ${ }^{7}$ resulting in a shortening of the action potential duration in the right ventricular 
epicardium, which causes a transmural voltage gradient, seen as ST elevation and re-excitation on the ECG. This voltage gradient creates a vulnerable window for extrasystoles or premature impulses to initiate phase 2 re-entry, triggering VF. ${ }^{9}$ Class IA (for example, ajmaline, procainamide) and class IC (for example, propafenone, flecainide) antiarrhythmic agents and heightened parasympathetic tone increase ST segment elevation and may precipitate VF. Sympathetic activation, stress testing, isoproterenol, and dobutamine may decrease ST segment elevation and result in transient normalisation of the ECG. ${ }^{10}{ }^{11}$ The VF frequently seen during sleep in patients with BS is probably due to a decrease in sympathetic tone. ${ }^{12}$

The typical presentation of BS is syncope or SCD, depending on the duration of VT. If VT is persistent, it eventually degenerates into VF and results in SCD. If VT is self terminating in a short period, it results in syncope or near-syncope. ${ }^{13}$ In addition, it has been suggested that there is a higher than normal incidence of supraventricular tachyarrhythmias in Brugada patients. ${ }^{14}$ Nearly $10 \%$ of patients with BS have concomitant atrial fibrillation. ${ }^{10}$ Therefore, BS should not be only considered in SCD victims or syncope patients, but also in patients who present to the ED with new onset atrial fibrillation with ST segment elevation in the right precordial leads.

Half of patients with BS have non-diagnostic resting ECG, and in $42 \%$ of cases, the ECG can normalise transiently. ${ }^{11}{ }^{15}$ Because of the intermittent and concealed nature of the ECG signs, diagnosis of BS may be difficult. A consensus report of the diagnostic criteria for BS is outlined in table $1 .{ }^{16}$

Patients with suspected BS should undergo a pharmacological challenge test with class IA antiarrhythmic drugs in the electrophysiology laboratory. ${ }^{5}$ It has been reported that propafenone has an unmasking effect and can reveal a concealed BS, ${ }^{17} 18$ as occurred in our patient. False positive pharmacological challenge tests have not been reported so far. ${ }^{5}$

Electrophysiological testing is useful for both further confirmation of the diagnosis and determination of treatment strategies. In the largest series yet reported in the literature, $30 \%$ of symptomatic Brugada patients developed a recurrent arrhythmic event (VF, SCD, or syncope due to ventricular arrhythmias) at a mean (SD) of 31 (41) months' follow up. In the same study, while $12 \%$ of asymptomatic patients who were induced by programmed ventricular stimulation developed their first arrhythmic event, only $1.1 \%$ of non-inducible asymptomatic patients developed arrhythmias. ${ }^{19}$ Treatment criteria for BS are shown in table $2 .^{519}$ Because of the autosomal dominant inheritance, other family members should be referred to a cardiologist for diagnostic testing. ${ }^{5}$

The mortality of BS is approximately $30 \%$ at 2 years following the diagnosis. ${ }^{6}$ An implantable cardioverter defibrillator (ICD) implant is the only effective treatment option for prevention of SCD in patients with BS. In one study, with use of an ICD, the mortality at 10 year follow up was $0 \% .{ }^{20}$ Antiarrhythmic drugs, including amiodarone and beta blockers have not been shown to reduce mortality or recurrence of ventricular arrhythmias. ${ }^{21}$

\section{CONCLUSION}

BS is a preventable cause of SCD. Failure to diagnose the syndrome results in a high mortality rate. Early recognition of this syndrome may contribute to a decrease in the frequency of idiopathic VF and may improve prognosis of patients with
BS. Therefore, emergency physicians should be familiar with the ECG findings of BS, and patients with suspected BS should be referred to a cardiologist. For all patients with new onset atrial fibrillation with RBBB, if chemical cardioversion is planned with propafenone in the ED, they should be also observed for ST segment elevation, which would be indicative of BS.

\section{Authors' affiliations}

E Aksay, S Yanturali, Department of Emergency Medicine, Dokuz Eylul University Hospital, Turkey

T Okan, Department of Cardiology, Dokuz Eylul University Hospital, Turkey

Competing interests: none declared

Correspondence to: Dr E Aksay, Emergency Physician, Dokuz Eylul University Medical School, Department of Emergency Medicine. 35340, Inciralti, Izmir, Turkey; ersin.aksay@deu.edu.tr

Accepted for publication 25 March 2004

\section{REFERENCES}

1 Butler JM. Brugada syndrome-the missed epidemic. J Accid Emerg Med 2000;17:426-8.

2 Zipes D, Wellens HJ. Sudden cardiac death. Circulation 1998;98:2334-51.

3 Alings M, Wilde A. "Brugada" syndrome: clinical data and suggested pathophysiological mechanism. Circulation 1999;99:666-73.

4 Brugada P, Brugada J. Right bundle branch block, persistent ST segment elevation and sudden cardiac death: a distinct clinical and electrocardiographic syndrome. J Am Coll Cardiol 1992;20:1391-6.

5 Brugada P, Brugada J, Brugada R. The Brugada syndrome. Card Electrophysiol Rev 2002;6:45-8.

6 Brugada P, Brugada R, Brugada J. The Brugada syndrome. Curr Cardiol Rep 2000;2:507-14.

7 Chen Q, Kirsch GE, Zhang D, et al. Genetic basis and molecular mechanisms for idiopathic ventricular fibrillation. Nature 1998;392:292-6.

8 Yan GX, Antzelevitch C. Cellular basis for the Brugada syndrome and other mechanisms of arrhythmogenesis associated with ST-segment elevation. Circulation 1999;100:1660-6.

9 Antzelevitch C. The Brugada syndrome. J Cardiovasc Electrophysiol 1998;9:513-16.

10 Brugada R, Brugada J, Antzelevitch C, et al. Sodium channel blockers identify risk for sudden death in patients with ST-segment elevation and right bundle branch block but structurally normal hearts. Circulation 2000;101:510-15.

11 Naccarelli GV, Antzelevitch C. The Brugada syndrome: clinical, genetic, cellular, and molecular abnormalities. Am J Med 2001; 1 10:573-81.

12 Matsuo K, Kurita T, Inagaki M, et al. The circadian pattern of the development of ventricular fibrillation in patients with Brugada syndrome. Eur Heart $J$ 1999;20:465-70.

13 Mattu A, Rogers RL, Kim H, et al. The Brugada syndrome. Am J Emerg Med 2003;21:146-51

14 Eckardt L, Kirchhof $P$, Loh $P$, et al. Brugada syndrome and supraventricular tachyarrhythmias: a novel association? J Cardiovasc Electrophysiol $2001 ; 12: 680-5$.

15 Sakabe M, Fujiki A, Tani M, et al. Proportion and prognosis of healthy people with coved or saddle-back type ST segment elevation in the right precordial leads during 10 years follow-up. Eur Heart J 2003;24:1488-93.

16 Wilde AA, Antzelevitch C, Borggrefe M, et al. Study Group on the Molecular Basis of Arrhythmias of the European Society of Cardiology. Proposed diagnostic criteria for the Brugada syndrome. Eur Heart J 2002;23:1648-54.

17 Guevara-Valdivia ME, Iturralde Torres P, de Micheli A, et al. Disclosure of "Brugada's syndrome" with intravenous propafenone. Arch Cardiol Mex 2002;72:45-8

18 Akdemir I, Davutoglu V, Aksoy M. Intermittent Brugada syndrome misdiagnosed as acute myocardial infarction and unmasked with propafenone. Heart 2002;87:543.

19 Brugada P, Brugada R, Mont L, et al. Natural history of Brugada syndrome: the prognostic value of programmed electrical stimulation of the heart. J Cardiovasc Electrophysiol 2003;14:455-7.

20 Brugada J, Brugada P, Brugada R. The syndrome of right bundle branch block ST segment elevation in $\mathrm{V} 1$ to $\mathrm{V} 3$ and sudden death-the Brugada syndrome. Europace 1999;1:156-66.

21 Brugada J, Brugada R, Brugada P. Right bundle-branch block and ST-segment elevation in leads V1 through V3: a marker for sudden death in patients without demonstrable structural heart disease. Circulation 1998;97:457-60. 


\title{
Trans-sternal cardiac injury caused by a hooked needle
}

\author{
H Yanar, M Aksoy, K Taviloglu, E S Unal, M Kurtoglu, K Nisli
}

Emerg Med J 2005;22:751-753. doi: 10.1136/emj.2004.014779

Cardiac injuries remain the most challenging of all injuries seen in the field of trauma surgery. Penetrating injury to the heart generally occurs less frequently than blunt injury and most commonly injures the large anterior right ventricle. We present an unusual, and to our knowledge a previously unreported, cause of cardiac penetrating trauma in a child, involving a hooked needle $($ a $15 \mathrm{~cm}$ long, metallic device usually used for crocheting or lacemaking). A ventricular septal defect was managed conservatively shortly after the primary cardiorrhaphy. Evaluation methods for this rare presentation and its possible surgical treatments are discussed.

C rdiac injuries remain the most challenging of all injuries seen in the field of trauma surgery and their management often requires immediate surgical intervention, excellent surgical technique, and the ability to provide excellent critical care to these patients postoperatively. ${ }^{1}$ Penetrating injury to the heart generally occurs less often than blunt injury and most commonly injures the large anterior right ventricle. ${ }^{2}$ Sewing needles, ${ }^{3}$ steel splinters, ${ }^{4}$ and crossbow bolts ${ }^{5}$ have been reported among foreign bodies penetrating the heart. Causes such as complication of a pectus excavatum operation, or an endomyocardial steet strut have been reported, ${ }^{6}$ although the most frequent causes of penetration are gunshots and stab injuries. ${ }^{78}$ Both Beck's triad and Kussmaul's sign are difficult to see in young children. $^{2}$

We present an unusual and to our knowledge a previously unreported cause of cardiac penetrating trauma in a child, involving a hooked needle (a $15 \mathrm{~cm}$ long, metallic device usually used for crocheting or lacemaking). A ventricular septal defect (VSD) was managed conservatively shortly after the primary cardiorrhaphy. Evaluation methods for this rare presentation and its possible surgical treatments are discussed.

\section{CASE REPORT}

A 5 year old girl was admitted to our emergency department with a hooked needle penetrated in her chest wall from the left edge of the sternal corpus, in a mediolateral and craniocaudal trajectory (fig 1). The accident had happened when she fell over while running at home with a hooked needle in her hand, just 40 minutes before admission.

The child was conscious and fully alert. She did not have respiratory distress except for mild pain during breathing. Her blood pressure was $105 / 60 \mathrm{~mm} \mathrm{Hg}$, and the heart rate was 120 beats/min. The exposed part of the hooked needle had a movement reflecting the pulsatile motion of the heart. There were no other cranial or abdominal pathological findings. Both lungs were well aerated, heart sounds were clearly heard without any murmur, and the heart was rhythmic on auscultation. After venous access was secured, a portable electrocardiography was performed and a normal sinusal rhythm was seen. Anteroposterior and lateral chest radiography revealed penetration of the sternal corpus and the possibility of cardiac penetration (fig 2). Cardiac and upper abdominal ultrasound (US) performed subxiphoidally did not reveal any pericardial fluid, haemothorax, or intraabdominal free fluid, but the tip of the hooked needle was visible inside the right ventricle. A central venous route was accessed via the left subclavian vein and the central venous pressure was measured as $6 \mathrm{~cm} \mathrm{H}_{2} \mathrm{O}$. The blood count was in the normal range (haematocrit 35\%, haemoglobin $11 \mathrm{mg} / \mathrm{dL}$, white blood cell count $10.1 / \mathrm{m}^{3}$ ). The computerised tomography (CT) scan showed a foreign body passing through the sternal corpus, and the tip of the hooked needle was in the right ventricle. The possibilities of pericardial tamponade, pneumothorax, and pleural effusion were excluded (fig 2).

The patient, who was conscious and in a stable condition, was taken to the operating room 40 minutes after admission. Gentle removal of the foreign body in the operating theatre was planned under mild anaesthesia, with conditions for general anaesthesia set in place in case of emergency. Four minutes after removing the hooked needle, a sudden bradycardia developed and central venous pressure rose to $15 \mathrm{~cm} \mathrm{H}_{2} \mathrm{O}$. The patient was intubated endotracheally and a left anterolateral thoracotomy via Sparango incision was performed. During the thoracotomy, pericardial tamponade was eased by pericardiotomy. There was a perforation measuring $3 \times 4 \mathrm{~mm}$ on the anterior wall of the right ventricle, which was repaired with horizontal Halsted mattress sutures, (Prolene no. 2-0), without need for a pericardial patch. The patient was taken to the intensive care unit (ICU) postoperatively.

After two uneventful postoperative days in the ICU, the patient developed tachypnoea and dyspnoea with auscultable rough crackles from either hemithorax. Consultation with the paediatric cardiology unit (PCU) revealed congestive heart failure, thus intravenous dopamine and dobutamine treatment was started. Echocardiography was performed the same day and showed a traumatic VSD of $3.5 \mathrm{~mm}$ in length in the muscular portion of the interventricular septum with rough margins and an evident left to right shunt with a pressure gradient of $77 \mathrm{mmHg}$. The right ventricle was mildly dilated and its anterior wall hypokinetic. The ejection fraction was found to be $67 \%$ (fig 3 ).

The treatment in the ICU relieved the symptoms and the child was discharged to the PCU with no surgical problem on the sixth postoperative day, continuing on digoxin, captopril, and prophylaxis for endocarditis.

After 30 days of follow up in the PCU, the anti-congestive therapy was stopped. The patient was discharged with an asymptomatic patent VSD, and close six monthly follow up with echocardiography for the first year was planned.

\section{DISCUSSION}

Penetrating cardiac trauma in children is seldom reported in the literature and the incidence of penetrating cardiac trauma in children is lacking. ${ }^{2}$ Data on the effects of acute traumatic injury to specific cardiac components come mostly from the adult literature and consists of atrioventricular valve insufficiency, aortic insufficiency, VSD, atrial septal defect, coronary artery injury, haemopericardium, cardiac rupture and cardiac contusion. ${ }^{129}$

Physiological condition, cardiovascular respiratory score and mechanism of injury plus initial rhythm are reported to 


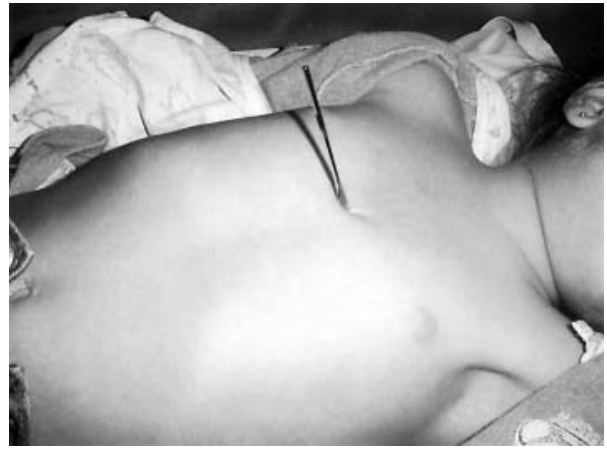

Figure 1 Appearance of the patient with the hooked needle on admission.

be significant predictors of outcome in penetrating cardiac injuries in adults. ${ }^{8}$ The case presented here, and our experience in cardiovascular trauma surgery supports that these predictive factors are strongly reliable. We also agree that the critical time period of pericardial tamponade acts on the patients' outcomes as a positive or negative predictive factor.

There are several methods of evaluating cardiac injuries. Subxiphoid pericardial window remains the gold standard of all procedures for the diagnosis and treatment but with the availability of ultrasound (US) in trauma centres, this technique has been relegated to a second line of evaluation. ${ }^{1}$ Surgeon performed US decreases the time between arrival and definitive treatment in patients with penetrating cardiac traumas. ${ }^{10}$

Three categories of electrocardiographic (ECG) interpretation exist in penetrating cardiac trauma pre and post operatively: acute myocardial infarction, pericarditis, repolarisation unspesific changes. ${ }^{11}$ But ECG abnormalities are said to occur less commonly in children than in adults, ${ }^{2}$ as we experienced.

Two dimensional echocardiography has been shown to have a $90 \%$ accuracy, a $97 \%$ specificity, and a $90 \%$ sensitivity in detecting penetrating cardiac injuries by Jimenez et al. ${ }^{12}$ Unfortunately we could not perform an echocardiography preoperatively because of the course of our cases, but echocardiography gave us the chance of detecting the VSD postoperatively, and we believe that it must be the first choice as a diagnostic tool in the follow up period of patients'.

Chest CT has been shown to have a high sensitivity, spesificity and accuracy rate in the setting of penetrating thoracic injury. ${ }^{13}$ CT findings of our patient were the same as we detected in the operation. We think that CT scans can be used for diagnosis of a haemodynamically stable patient who can be closely monitored during the transfer and scanning period.

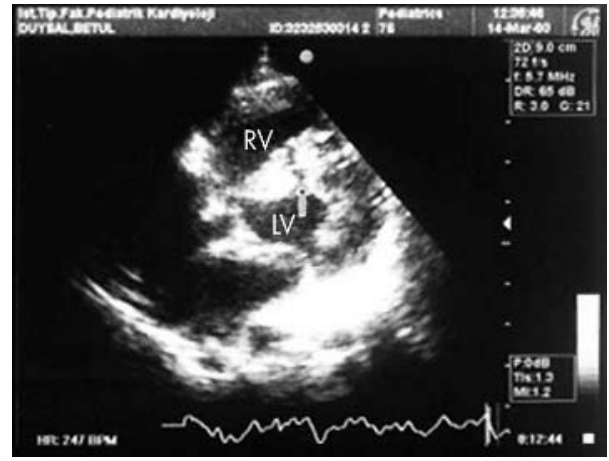

Figure 3 Echocardiography showing VSD 2 days after surgery.

Unlike our case, emergency department thoracotomy can be used as a diagnostic and therapeutic tool in unstable patients and it continues to be widely used in children. ${ }^{1}$

Haemodynamically stable selected patients with isolated penetrating cardiac injuries can be followed up conservatively in ICU as in penetrating abdominal injuries. Series aiming to emphasise the point that there is a place for conservative management of selected cases with penetrating cardiac injuries has been reported, ${ }^{14}$ and we will report the results of our conservative management in penetrating cardiac trauma in the near future. Therefore, we tried to give the chance of non-operative management to our patient, but due to the reasons mentioned above, thoracotomy was performed.

Another point of debate is the reparation of injuries with life threatening free wall wounds of the heart. It is usually quite hard to detect accompanying intracardiac lesions in emergency surgery situations because of the negative effects of increased operation time to the traumatic patient. Intraoperative cardiac sampling following penetrating wound as a technique for early detection of traumatic intracardiac shunts in a case has been reported. ${ }^{15}$ In the literature numerous studies have reported residual intracardiac lesions which are not identified in the first operation from $4 \%$ to $56 \%$ of cases. Functional sequelae in such patients have rarely been described. ${ }^{11} 16$

Tesinski reports that almost $25 \%$ of the patients are later diagnosed to have suffered injury also to one of the intracardiac structures, a VSD caused by penetrating injury to the heart is found to in $2-10 \%$ of the survivors and interval repair should be performed according to the clinical status of the patient and mostly depends on the size of the left to right shunt. ${ }^{3}$ Delayed repair of cardiac trauma allows tissue healing to a varying degree which may or may not be beneficial. VSDs can shrink or even close spontaneously with time, but this is unlikely to occur with tricuspid valve injuries. ${ }^{17}$
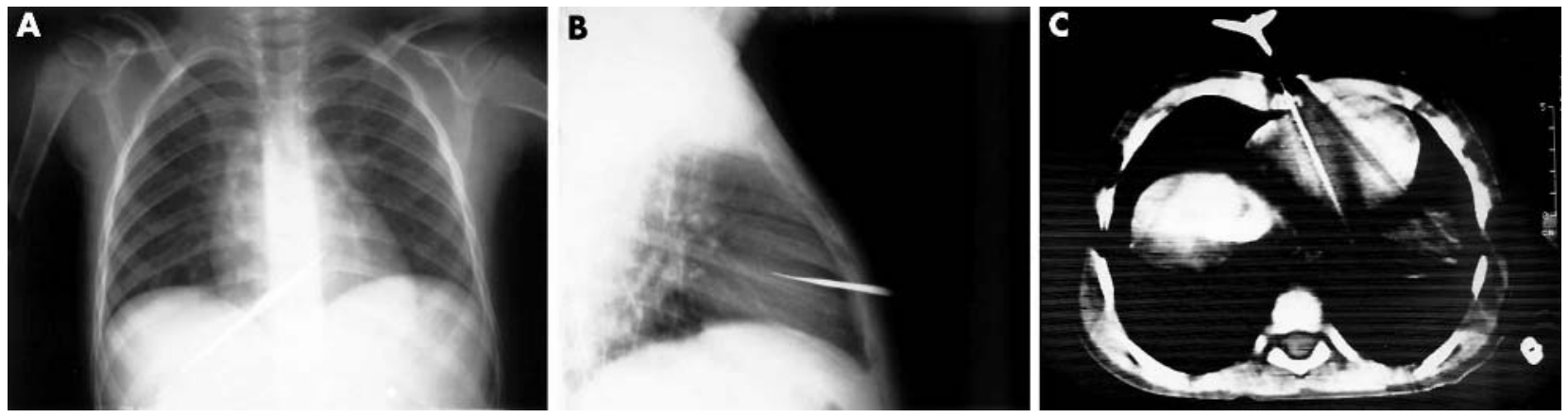

Figure 2 (A) Anteroposterior chest radiograph; (B) lateral chest radiograph; (C) CT scan showning intracardiac hooked needle. 
We agree the authors who are in favor of delayed repair as it is more rationalist to repair residual intracardiac lesions in an elective operation. However the patients should be followed closely for delayed sequel of these lesions in a multidiciplinary fashion.

\author{
Authors' affiliations \\ H Yanar, M Aksoy, K Taviloglu, E S Unal, M Kurtoglu, Department of \\ General Surgery, Emergency Surgery Unit, Istanbul Medical Faculty, \\ Istanbul University, Istanbul, Turkey \\ K Nisli, Pediatric Cardiology Unit, Department of Pediatrics, Istanbul \\ Medical Faculty, Istanbul University, Istanbul, Turkey \\ Competing interests: none declared \\ Correspondence to: Dr H Yanar, Trauma and Emergency Surgery Unit, \\ Department of General Surgery, Istanbul Medical Faculty, University of \\ Istanbul, Capa, Istanbul, 34390 Turkey; htyanar@yahoo.com \\ Accepted for publication 29 April 2004

\section{REFERENCES} \\ 1 Asensio JA, Soto SN, Forno W, et al. Penetrating cardiac injuries: a complex \\ challenge. Injury $2001 ; 32: 533-543$. \\ 2 Baum VC: Cardiac trauma in children. Paediatric Anaesthesia \\ 2002;12:110-117. \\ 3 Sbokos CG, Azariades M, Chlapoutakis E, et al. The removal of sewing \\ needles from two children's hearts. Thorac Cardiovasc Surg \\ 1984;32:373-375. \\ 4 Garcia-Lledo JA, Moya Mur JL, Recena B, et al. Penetrating trauma by foreign \\ body in the left heart ventricle. Rev Esp Cardiol 1997;50:137-139.
}

5 Besler K, Kleiber M, Zerkowski HR, et al. Non-lethal penetrating cardiac injury from a crossbow bolt. Int J Legal Med 1998;111:88-90.

6 Onursal E, Toker A, Bostancı K, et al. A complication of pectus excavatum operation: Endomyocardial Steel Strut. Ann Thorac Surg 1999:68:1082-1083

7 Tesinsky L, Pirk J, al-Hiti $\mathrm{H}$, et al. An isolated ventricular septal defect as a consequence of penetrating injury to the heart. Eur J Cardiothorac Surg 1999; 15:221-223.

8 Asensio JA, Murray J, Demetriades D, et al. Penetrating Cardiac Injuries: a prospective study of variable predicting outcomes. J Am Coll Surg 1998;186:24-34.

9 Asensio JA, Stewart BM, Murray J, et al. Penetrating cardiac injuries. Surg Clin North Am 1996;76:685-724.

10 Carrillo EH, Guinn BJ, Ali AT, et al. Transthoracic ultrasonography is an alternative to subxiphoid ultrasonography for the diagnosis of hemopericardium in penetrating precordial trauma. Am J Surg 2000; 179:34-36.

11 Duque HA, Florez EL, Moreno A, et al. Penetrating cardiac trauma: Follow-up study including electrocardiography, echocardiography, and functional test. World J Surg 1999;23:1254-1257.

12 Jimenez E. Martin M, Krukenkamp I, et al. Subxiphoid pericardiotomy versus echocardiography: A prospective evaluation of the diagnosis of occult penetrating cardiac injury, Surgery 1990;108:676-680.

13 Nagy KK. Gilkey SH, Roberts RR, et al. Computed tomography screens stable patients at risk for penetrating cardiac injury. Acad Emerg Med 1996;3:1024-1027

14 Michelow BJ, Bremmer CG. Penetrating cardiac injuries: selective conservatism - favorable or foolish? J Trauma 1987;27:398-401.

15 Baxter BT, Moore EE, Moore FA, et al. Intraoperative cardiac sampling following penetrating wounds : a technique for early detection of traumatic intracardiac shunts-case report. J Trauma 1989;29:1719-1720.

16 Fallahnejad M, Kutty A, Wallace HW. Secondary lesions of penetrating cardiac injuries. Ann Surg 1980;191:228-233.

17 Doty JR, Cameron DE, Elmaci T, et al. Penetrating trauma to the tricuspid valve and ventricular septum: delayed repair. Ann Thorac Surg 1999;67:252-253.

\section{More than just an ocular solution}

\section{Pekdemir, S Yanturali, G Karakus}

Apraclonidine eye drop is an alpha adrenergic agonist derived topical clonidine, used for the treatment of intraocular pressure elevation. We report what is to our knowledge the first case of systemic toxicity of apraclonidine resulted from repeated local administration. Clinical manifestation of toxicity was similar to oral clonidine overdose. Toxicities of ocular drugs should always be considered when a patient presents with new systemic problems.

A praclonidine is a widely used topical ophthalmic alpha agonist used to reduce intraocular high pressure. We present a case of systemic toxicity of this drug. Our literature search revealed no reported case of systemic toxicity from local apraclonidine administration, thus we believe this is the first such case.

\section{CASE REPORT}

A 56 year old woman was taken to the emergency department (ED) of Kocaeli University because of altered mental status, difficulty in speaking, and drowsiness. She had undergone laser capsulotomy for cataract removal l day previously, after which apraclonidine hydrochloride ophthalmic solution (Iopidine 0.5\%; Alcon) was prescribed. The patient misunderstood the instruction of the medication, and administered the drug every 5 minutes. After 4 hours, she developed generalised weakness and headache.
On admission to the ED, her blood pressure (BP) was 170/ $110 \mathrm{mmHg}$ and heart rate (HR) 60 beats/min. The patient's complaint was considered to be associated with high blood pressure. She was given $25 \mathrm{mg}$ captopril and discharged.

After discharge, she had continued to apply her eye medication at the same dosage. Eight hours later, she developed lowered consciousness, difficulty in speaking, and drowsiness. She had a history of hypertension for which she had been taking losartan. On her second admission to the ED, her vital signs revealed hypotension (BP 80/60 mm Hg; HR 65 beats/ min. She was drowsy (Glasgow Coma Score 13). No focal neurological deficit or other abnormality was found on physical examination. She was placed on a cardiac monitor and a saline infusion bolus was initiated. Initial serum electrolytes and complete blood count were within normal limits except for mild increased blood urea nitrogen and mild anaemia. ECG showed sinusal bradycardia without any significant ischemic findings, and computed tomography of the brain was normal. During observation in the ED, she had developed bradycardia (HR 40 beats/min; BP could not be measured at this stage). After normal saline bolus and intravenous atropine $1 \mathrm{mg}$, blood pressure and heart rate returned to normal (BP 140/ $100 \mathrm{~mm} \mathrm{Hg}$, HR 100 beats/min).

Detailed history discovered that she had used the entire $5 \mathrm{ml}$ apraclonidine solution within 12 hours after the operation.

Abbreviations: BP, blood pressure; ED, emergency department; $H R$, heart rate; IOP, intraocular pressure 
There was no other reason to explain her central nervous system depression and cardiovascular compromise. She gradually improved, with all symptoms and findings disappearing within 48 hours. After full recovery, she was discharged.

\section{DISCUSSION}

It was estimated by nowadays, 200000 cataract operations performed annually within the UK National Health Service. Laser capsulotomy is a widely used technique for cataract removal. A rise in intraocular pressure (IOP) is a common side effect of this technique. Apraclonidine $1 \%$ is a potent and relatively selective alpha-2 agonist used for the control or prevention of postsurgical elevations in IOP, and was derived from the systemic antihypertensive drug clonidine. It was the first agent to be approved for reducing incidence of postoperative IOP spiking following laser capsulotomy. ${ }^{2}$ Apraclonidine is more polar and less lipophilic than clonidine, which probably allows less penetration into systemic circulation. It also does not cross the blood brain barrier and therefore does not cause systemic hypotension. ${ }^{3}$

Oral clonidine toxicity manifests as central nervous system depression, cardiovascular compromise, and respiratory depression. Signs and symptoms of a clonidine overdose include altered mental status, bradycardia, hypotension, respiratory depression, hypothermia, and miosis. ${ }^{4}$ Intoxication from patch forms of clonidine have been reported. In these cases, depression of mental status, bradycardia, and hypotension predominated, similar to oral clonidine overdose. ${ }^{5-8}$

The clinical presentation of our patient was similar to oral clonidine intoxication. The patient developed lowered consciousness, hypotension, and bradycardia. She was managed with saline infusion and atropine for symptomatic bradycardia and hypotension. Her cardiovascular and central nervous system findings improved completely during hospitalisation. Her increased blood pressure during the initial episode can be attributed to paradoxical hypertension, similar to oral clonidine overdose. Additionally, administration of antihypertensive treatment in this stage and use of her routine anti-hypertensive drug could have contributed to development of the systemic toxicity.

Eye drops are regarded as a safe medication with low potential for systemic effects. However, even topical eyedrops may lead to systemic toxicity if used in extraordinarily high quantities. Topical apraclonidine, when used in excess, may induce lowered consciousness, hypotension, and symptomatic bradycardia. The clinical presentation and treatment principles of the systemic toxicity of apraclonidine overdose are similar to clonidine.

\section{CONCLUSION}

Ocular eye drops are widely used worldwide, and patients may not consider them to be medications that can cause systemic toxicity. Emergency physicians may encounter systemic adverse effects of topical ophthalmic drugs including apraclonidine. Appropriate precautions and patient education can help to minimise systemic toxicity when using ocular medication.

\section{Authors' affiliations}

M Pekdemir, Department of Emergency Medicine, Kocaeli Universtiy, Kocaeli, Turkey

S Yanturali, Department of Emergency Medicine, Dokuz Eylul University, Izmir, Turkey

G Karakus, Department of Internal Medicine, Kocaeli Universtiy, Kocaeli, Turkey

Competing interests: none declared

Correspondence to: Dr S Yanturali, Dokuz Eylul University Medical School, Department of Emergency Medicine, 35340, Inciralti, Izmir, Turkey; sedat.yanturali@deu.edu.tr

Accepted for publication 16 May 2004

\section{REFERENCES}

1 Desai P, Minassian DC, Reidy A. National cataract surgery survey 1997-8: a report of the results of the clinical outcomes. Br J Ophthalmol 1999;83:1336-40.

2 Ge J, Wand M, Chiang R, et al. Long-term effect of $\mathrm{Nd}$ :YAG laser posterior capsulotomy on intraocular pressure. Arch Ophthalmol 2000;1 18:1334-7.

3 Alward WL. Medical management of glaucoma. N Engl J Med 1998;339:1298-307.

4 Nichols MH, King WD, James LP. Clonidine poisoning in Jefferson County, Alabama. Ann Emerg Med 1997;29:511-17.

5 Raber JH, Shinar C, Finkelstein S. Clonidine patch ingestion in an adult. Ann Pharmacother 1993;27:719-22.

6 Killian CA, Roberge RJ, Krenzelok EP, et al. "Cloniderm" toxicity: another manifestation of clonidine overdose. Pediatr Emerg Care 1997;13:340-1.

7 Kraft ME. A 9-month-old with bradycardia and periodic apnea. J Emerg Nurs 1998;24:457-9.

8 Broderick-Cantwell JJ. Case study: accidental clonidine patch overdose in attention-deficit/hyperactivity disorder patients. J Am Acad Child Adolesc Psychiatry 1999;38:95-8.

\section{Early carbon monoxide intoxication: happy to be poisoned?}

\section{S F J Clarke, A Crosby, D Kumar}

Carbon monoxide poisoning is the commonest cause of death by poisoning in the UK and chronic exposure is thought to be a frequently missed diagnosis. Early recognition of carbon monoxide poisoning is vital to institute prompt treatment and to prevent exposure to others. An incident of mass exposure to carbon monoxide is presented where euphoria, lasting several hours, was the only symptom reported in approximately one quarter of the casualties. This has not been reported previously and we believe that mild carbon monoxide intoxication should be included in the list of differential diagnoses of inappropriate euphoria.
${ }^{2}$ arbon monoxide poisoning is the commonest cause of death by poisoning in the UK, ${ }^{1}$ and chronic exposure is thought to be a frequently missed diagnosis. Although much has been written about the signs and symptoms of both acute and chronic intoxication, the features of early, mild, acute exposure have received much less attention. Early recognition of carbon monoxide poisoning is vital to institute prompt treatment ${ }^{2}$ and to prevent exposure to others. ${ }^{3}$

We describe an episode of mass exposure to carbon monoxide that resulted in previously unreported changes in mood, which may provide a useful warning symptom. 


\section{CASE REPORT}

The emergency services were called to a secondary school (for children aged 11-18 years) with special needs. A high proportion of the children had severe learning difficulties and physical disabilities. At lunchtime, the catering staff at the school had noticed a strange smell and feelings of dizziness, mild headache, and euphoria; this gradually became worse over approximately 30 minutes, at which point the area was evacuated and the kitchen boiler was switched off. After this, no one developed further symptoms, although the emergency services were called about 1 hour later because of persistent symptoms in some of those exposed.

Monitoring was carried out by the local authority within the first hour of the alarm being raised, and this showed the presence of carbon monoxide in the dining room area. At the time, 43 pupils and 35 staff member had been in the dining room; all were considered to have been exposed, although none had become drowsy, lost consciousness, or experienced fits. The affected individuals were gathered together in the school gymnasium, which was well ventilated and away from the source of the exposure, and triage was carried out there. It was deemed impractical to try to take blood samples from so many severely disabled children who seemed to be otherwise well. The staff agreed to have venous blood taken for carboxyhaemoglobin levels after the National Poisons Information Service was consulted to confirm that venous levels were accurate enough for the purposes of screening. ${ }^{4}$ The appropriate bottles were collected from the biochemistry laboratory at the local hospital, and the attending paramedics took the samples 3-4 hours after first exposure. All of the results were $<5 \%$ ( $1-2 \%$ can be considered normal for urban residents, while smokers may have levels of $6-8 \%$ ). The half life of carbon monoxide in a subject breathing air is 5 hours ${ }^{5}$ (none of the patients was given supplemental oxygen), so these results were in the upper range of normal, which was thought to indicate mild exposure only.

Of the 35 staff members tested, 8 (23\%) reported feeling light headed and euphoric. The teachers and the carers were questioned by two of the paramedics about any changes to the behaviour and demeanour of their children. Only five children raised concerns, all about conjunctival injection, and were assessed by the medical team from the Chemical Hazards and Poisons Division of the Health Protection Agency who had attended the scene. The children were reassured and sent home, apart from one child, who was sent to the local emergency department because he suffered from Eissenmenger's syndrome and was complaining of persistent mild headache. He was subsequently discharged after a period of observation.

Because of the high dependency needs of the children, carers routinely escort them home on school buses. The local consultant in communicable disease control and the on call public health team contacted the parents/carers of all the children later in the day to enquire about any unusual symptoms in the children and to address concerns. All parents/carers of the 41 children were contacted; of these, 10 $(24 \%)$ reported that the children appeared happier or more elated than usual for the rest of the evening.

\section{DISCUSSION}

It is well recognised that carbon monoxide poisoning is commonly missed as a diagnosis. ${ }^{6}$ A literature search using the Medline and Embase databases was undertaken, as was a hand search of the papers collected in the carbon monoxide file at the National Poisons Information Service, London. This revealed a large number of articles concerning the effects of acute and chronic exposure to carbon monoxide. The majority consisted of serious cardiorespiratory and neurological effects due to significant or prolonged poisoning, and, although a small number of papers described unspecified neuropsychiatric sequelae, ${ }^{2-11}$ no mention of euphoria could be discovered.

It is interesting to note that it was the exceptional circumstances of this episode of carbon monoxide exposure that prompted the follow up health questionnaire to be performed, and that euphoria was repeatedly reported in both the children and the staff. As mood elevation has not been reported as a symptom of carbon monoxide poisoning, not all the parents were specifically asked about euphoria; the symptom was reported by the parents when they were questioned about any unusual behaviour in the children.

Euphoria tends to be associated with ingestion of certain drugs of misuse and with forms of acute psychosis, and we suggest that the list of potential differential diagnoses should include early carbon monoxide poisoning. It is an easily overlooked diagnosis because many of the clinical features are non-specific, but it is an easy one to exclude as blood levels are readily measurable in most hospitals.

In this case series of 78 people with early acute intoxication with carbon monoxide, euphoria was noted to be a relatively common occurrence, a symptom that to our knowledge had not been previously reported.

\section{Authors' affiliations}

S F J Clarke, Health Protection Agency, Division of Chemical Hazards and Poisons (London), London, UK

A Crosby, London Ambulance Service NHS Trust, London, UK D Kumar, North West London Health Protection Unit, London, UK

Competing interests: none declared

Correspondence to: Dr S J Clarke, Consultant in Emergency Response, Health Protection Agency, Division of Chemical Hazards and Poisons (London), Avonley Road, London, SE14 5ER; sfjclarke@doctors.org.uk

Accepted for publication 9 July 2004

\section{REFERENCES}

1 Jones AL, Dargan PI. Churchill's pocketbook of toxicology. New York: Churchill Livingstone, 2001.

2 Thom SR, Tber RL, Mendiguren II, et al. Delayed neuropsychologic sequelae after carbon monoxide poisoning: prevention by treatment with hyperbaric oxygen. Ann Emerg Med 1995;25:474-80.

3 Ely EW, Moorehead B, Haponik EF. Warehouse workers' headache: emergency evaluation and management of 30 patients with carbon monoxide poisoning. Am J Med 1995;98:145-55.

4 Touger M, Gallagher EJ, Tyrell J. Relationship between venous and arterial carboxyhemoglobin levels in patients with suspected carbon monoxide poisoning. Ann Emerg Med 1995;25:481-3.

5 Crawford R, Campbell DGD, Ross J. Carbon monoxide poisoning in the home: recognition and treatment. BMJ 1990;301:977-9.

6 Wright J. Chronic and occult carbon monoxide poisoning: we don't know what we're missing. Emerg Med J 2002;19:386-90.

7 Perry GF. Occupational medicine forum. What are the potential delayed health effects of high-level carbon monoxide exposure? J Occup Med 1994;36:595-7.

8 Ernst A, Zibrak JD. Carbon monoxide poisoning. N Engl J Med 1998;339:1603-8.

9 Myers RAM, DeFazio A, Kelly MP. Chronic carbon monoxide exposure: a clinical syndrome detected by neuropsychological tests. J Clin Psychol 1998;54:555-67.

10 Amitai Y, Zlotogorski Z, Golam-Katzav V, et al. Neuropsychological impairment from acute low-level exposure to carbon monoxide. Arch Neurol 1998;55:845-8.

11 Raub JA, Benignus VA. Carbon monoxide and the nervous system. Neurosci Behav Rev 2002;26:925-40. 


\title{
Acute aortic dissection provoked by sneeze: a case report
}

\author{
A Baydin, M S Nural, H Güven, T Deniz, F Bildik, A Karaduman
}

Emerg Med J 2005;22:756-757. doi: 10.1136/emj.2004.014829

The response of the abdominal viscera and the contraction of the intercostal muscles during the respiratory phase of sneezing increases intrathoracic pressure, which may lead to several complications. However, there are no reports in the literature concerning aortic dissection after sneezing. We report a patient in whom the development of dissection was secondary to sneezing, although hypertension was present as a risk factor, and we discuss the relationship between sneezing and aortic dissection. To our knowledge, this is the first report of aortic dissection provoked by sneezing in the literature.

A ortic dissection occurs from a rupture of the intima, which allows blood to enter the media and dissect between the intimal and the adventitial layers. ${ }^{1}$ The estimated incidence of aortic dissection is 5 to 30 cases per million population per year. Chronic systemic hypertension is the most common factor predisposing to aortic dissection and is present in $62-78 \%$ of patients with aortic dissection. ${ }^{2}$

The increase in intrathoracic pressure during sneezing may lead to serious complications. We present a case in which the development of aortic dissection was considered secondary to sneezing, although hypertension was present as a risk factor, and we discuss the relationship between sneezing and aortic dissection. To our knowledge, this is the first reported case of aortic dissection provoked by sneezing.

\section{CASE REPORT}

A 51 year old man was admitted to the emergency department (ED) with severe, sudden onset chest pain and dyspnoea following sneezing. The patient reported that the pain was very severe and by the time he arrived at the ED (a period of about 20 minutes), had spread towards his back. He had a history of hypertension diagnosed 5 years previously, which was regulated with nifedipine (Adalat) and lisinopril $20 \mathrm{mg}$ plus hydrochlorothiazide $12.5 \mathrm{mg}$ (Sinoretik).

On physical examination, blood pressure was 190/ $110 \mathrm{mmHg}$, pulse rate 90 beats $/ \mathrm{min}$, respiration rate 24 breaths/min and temperature $36{ }^{\circ} \mathrm{C}$. He was conscious, cooperative, and in moderate health. All other physical findings were normal. Laboratory findings showed glucose of $1.14 \mathrm{~g} / \mathrm{l}$ (normal 0.7-1.1 g/l) and albumin $33 \mathrm{~g} / \mathrm{l}$, while other findings were within normal limits. There was no abnormal finding on 12 lead electrocardiography.

Chest $x$ ray revealed a widening in the aortic knob and the lateral margin of the descending aorta (fig 1A). Spiral computed tomography (CT) was performed to rule out aortic dissection, but showed an intimal flap that seperated the aortic lumen into two parts, extending from the proximal descending aorta to the left common iliac artery. The ascending aorta and supraaortic branches were normal (fig 1B). Using transoesophageal echocardiography, a dissection was detected starting just after the subclavian artery orifice and extending downwards distally.

After clinical and radiological evaluation, a Stanford type B aortic dissection was diagnosed and medical treatment commenced in the ED, after which the patient was admitted to a hospital ward. During follow up, the chest pain had not subsided and the patient's blood pressure could not be controlled despite appropriate treatment. A control CT scan taken 1 week later showed some abnormalities in the descending aortic contour at the level of right pulmonary artery orifice and a small effusion in the left pleural space (fig lC). The patient underwent surgery for possible aortic aneurysm rupture.
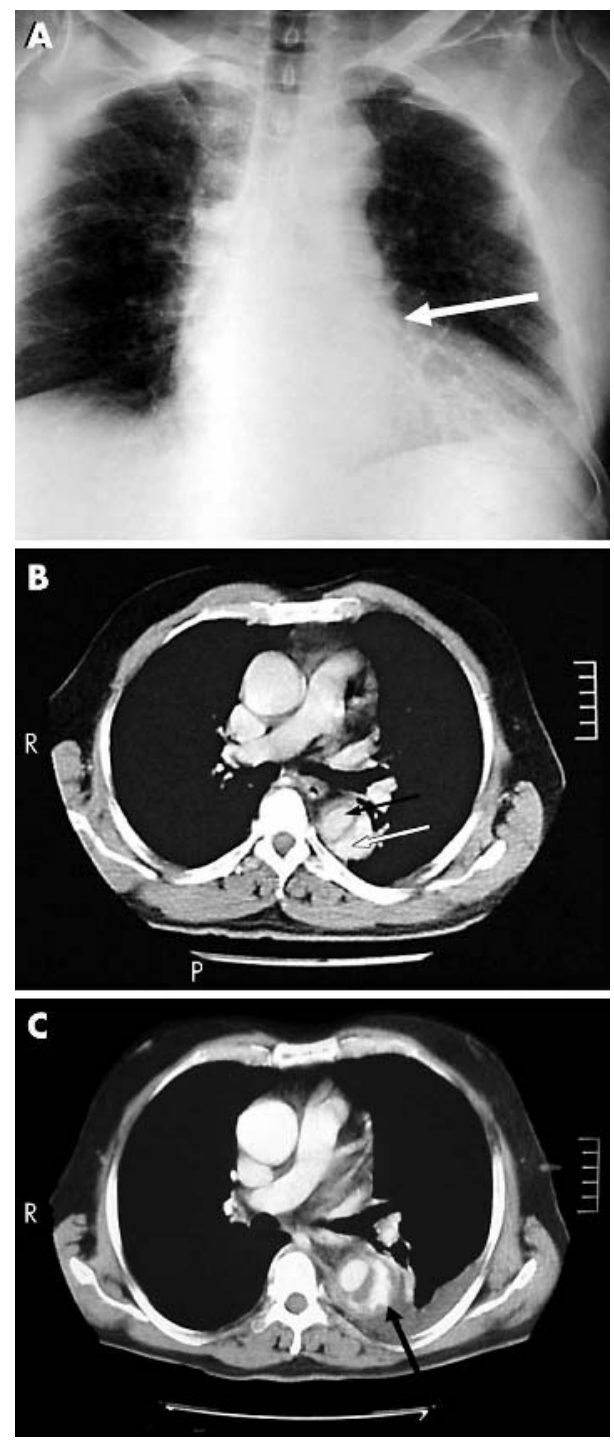

Figure 1 (A) Chest radiograph shows widening of the aortic knob and the lateral margin of the descending aorta (white arrow). (B) Type B aortic dissection. Axial contrast enhanced spiral CT scan shows an intimal flap in the descending aorta that separated the lumen into two parts; true (black arrow) and false (white arrow) lumens. The ascending aorta is normal. (C) CT scan obtained at the level of the right pulmonary artery showing mild irregularities in the lateral contour of the descending aorta (black arrow) and associated left pleural effusion. 


\section{DISCUSSION}

During the sneeze reflex, the intrathoracic pressure is raised, which may lead to several complications. Brock et al reported a case of chest pain following sneezing, which occurred from fractures of ribs $8,9,10$, and 11 . There are some reports of lung herniation triggered by sneezing, as demonstrated on chest $x$ ray. $^{3}$

The increase in intrathoracic and intra-abdominal pressure raises the venous pressure in these spaces, leading to a further increase in the epidural veins and a corresponding increase in intracranial pressure. ${ }^{4} \mathrm{~A}$ case has been reported with a temporary hemiparesis caused by a sneezing induced intracranial aneurysm. ${ }^{5}$ Sharir et al reported a patient who had an attack of acute angle closure glaucoma precipitated by sneezing, which may have been the result of an increase in the ocular venous return precipitated by the increase in the intrathoracic pressure. ${ }^{6}$ Whitehead et al ${ }^{7}$ and Azem and Calderelli $^{8}$ have reported patients who developed hearing loss in association with stapes fracture due to increased intracranial pressure following sneezing.

Coughing, sneezing, and the other Valsalva manoeuvres not only increase intrathoracic pressure but also alter the haemodynamics. Initially, the arterial pressure increases with a rise in respiratory tract pressure, but then decreases following a decline in venous return. ${ }^{4}$ It has also been reported in another study that systolic and diastolic arterial pressure increase during the Valsalva manoeuvre. ${ }^{9}$ Systemic hypertension, one of the most common predisposing factors of acute aortic dissection, increases the tension on the aortic wall. We believe that in our hypertensive patient, the increase in arterial pressure caused by the rise in intrathoracic pressure during sneezing, enhanced the aortic wall tension, and that this sudden increase of pressure on the aortic wall triggered the intimal tear.

Aortic dissection is an important disease because, although rare, it may be life threatening. In over $38 \%$ of patients the diagnosis is missed at the first evaluation. ${ }^{2}$ In untreated patients, the mortality rate is $25 \%$ iwithin 24 hours, $70 \%$ by 2 weeks and $90 \%$ after 2 weeks. ${ }^{10}$

Chest pain is the most common symptom in aortic dissection cases presenting to the ED. Typically, the pain starts suddenly and is unbearable. Pain is the most intense when the symptoms begin. The localisation of the pain is related to the region in which the intimal rupture occurs; if the tear is above the aortic valve the pain is felt anteriorly, but if it is distal to the left subclavian vein it is felt in the back. Spreading of the pain may be a sign of progressive dissection. ${ }^{11}$ It has been reported that $>90 \%$ of the patients with acute aortic dissection undergo intense chest pain. ${ }^{11}{ }^{12}$ In our patient, the chest pain spread to the back, and the dissection was detected in the descending aorta.

It has been reported that $>90 \%$ of the patients with aortic dissection have widening of the mediastinum and aortic knob detected by chest radiography. ${ }^{11}$ In a study by Kodolitsch et al, it was found that that mediastinal and/or aortic widening was related to dissection in $39 \%$ of cases. In addition, it has been found that the existence of chest pain and changes in pulsation and blood pressure are related to the dissection in $83-100 \%$ of cases. ${ }^{12}$ In our case, there was a typical spontaneous and spreading type of chest pain. A widening of the aortic knob and the descending aortic lateral wall was revealed by chest radiography. However, the blood pressure was high but the pulse was normal.

\section{CONCLUSION}

Aortic dissection should be considered a possible diagnosis in patients who present to the ED with complaints of atypical chest pain after sneezing. If the patient's history implies intrathoracic pressure increase and other suggestive findings are present, as in our case, noninvasive diagnostic methods such as CT, transoesophageal echocardiography and magnetic resonance imaging should be performed promptly to rule out aortic dissection, which is a very severe life threatening condition. Aortic dissection may be added to the complications seen after sneezing.

\section{Authors' affiliations \\ A Baydin, H Güven, T Deniz, F Bildik, A Karaduman, Department of Emergency Medicine, Faculty of Medicine, Ondokuz Mayis University,} Samsun, Turkey

M S Nural, Department of Radiology, Faculty of Medicine, Ondokuz Mayis University, Samsun, Turkey

Competing interests: none declared

Presented at the First National Emergency Medicine Congress, 22-25 October 2003, Konya, Turkey.

Correspondence to: Dr A Baydin, Department of Emergency Medicine, Faculty of Medicine, Ondokuz Mayis University, 55139 Samsun, Turkey; abaydin@omu.edu.tr

Accepted for publication 29 March 2004

\section{REFERENCES}

1 Johnson GA. Aortic dissection and aneurysms. In: Tintinalli JE, Kelen GD, Stapczynski JS, eds. Emergency medicine: a comprehensive study guide, 5th ed. New York: McGraw-Hill, 2000:412-16.

2 Khan IA, Nair CK. Clinical, diagnostic and management perspectives of aortic dissection. Chest 2002;122:311-28.

3 Brock MV, Heitmiller RF. Spontaneous anterior thoracic lung hernias. J Thorac Cardiovasc Surg 2000;1 19:1046-7.

4 Andreoli CM, Leff GB, Rizzo JF 3rd. neeze-induced visual and ocular motor dysfunction. Am J Ophthalmol 2002;133:725-7.

5 Bradley WG Jr, Bank WO, Fischbeck KH. Sneeze-induced hemiparesis from unruptured intracranial aneurysm. J Neuroradiol 1982;9:323-7.

6 Sharir M, Hungtington AC, Nardin GF, et al. Sneezing as a cause of acute angle-closure glaucoma. Ann Ophthalmol 1992;24:214-15.

7 Whitehead E. Sudden sensorineural hearning loss with fracture of the stapes footplate following sneezing and parturition. Clin Otolaryngol 1999;24:462-4.

8 Azem K, Caldarelli DD. Sudden conductive hearing loss following sneezing. Arch Otolaryngol 1973;97:413-14.

9 Kern MJ, Gudipati C, Tatineni S, et al. Effect of abruptly increased intrathoracic pressure on coronary blood flow velocity in patients. Am Heart J 1990;119:863-70.

10 Sommer T, Fehske W, Holzknecht N, et al. Aortic dissection: A comparative study of diagnosis with spiral CT, multiplanar transesophageal echocardiography and MR imaging. Radiology 1996;199:347-52

11 Ledbetter S, Stuk JL, Kaufman JA. Helical (spiral) CT in the evalution of emergent thoracic aortic syndromes. Radiol Clin N Am 1999;37:575-89.

12 Kodolitsch YV, Schwartz AG, Nienaber CA. Clinical prediction of acute aortic dissection. Arch Intern Med 2000;160:2977-82. 